\title{
EUCALYPTUS CHIP ASHES IN CEMENTITIOUS COMPOSITES
}

\author{
Domingos Sávio de Resende ${ }^{1 \mathrm{a}}$; Herbet Radispiel Filho ${ }^{1 \mathrm{~b}}$; \\ José Genário Keles ${ }^{10}$; Augusto Cesar da Silva Bezerra ${ }^{1 d}$; \\ Maria Teresa Paulino Aguilar ${ }^{2 \mathrm{e}}$; Antonio Maria Claret de Gouveia ${ }^{3 \mathrm{f}}$; \\ (1) CEFET-MG, Av. Amazonas 5253 - Nova Suiça - Belo Horizonte - MG - Brasil CEP: 30.421-169 \\ (2) UFMG, Av. Antônio Carlos, 6627 - Pampulha - Belo Horizonte - MG - Brasil CEP 31270-901 \\ (3) UFOP, Praça Tiradentes, 20 - Centro - Ouro Preto - MG - Brasil CEP 35400-000 \\ e-mail: ${ }^{a}$ savio@araxa.cefetmg.br; ${ }^{b}$ radispiel@gmail.com; ${ }^{c}$ caseles@uol.com.br; \\ daugustobezerra@des.cefetmg.br; ${ }^{\mathrm{e}}$ teresa@ufmg.br; ${ }^{\mathrm{f}}$ claretgouveia@uol.com.br
}

\begin{abstract}
Keywords: eucalyptus chip ashes, pozzolan and cementitious composites
\end{abstract}
\begin{abstract}
The Alto Paranaiba and Triângulo Mineiro mesoregion in the state of Minas Gerais and the State of São Paulo have a number of industries with eucalyptus chip fired boilers that produce great amounts of ash. Since thermoelectric ashes generally have good pozzolanic activity, this paper studied the mechanical behavior of cementitious composites made with raw eucalyptus chip ash as a partial replacement for Portland cement and processed under two different conditions. The mechanical behavior of the composites was measured from tests on specimens for their compressive strength, tensile strength to diametral stress and to bending. Results show ashes could be used as mineral additives.
\end{abstract}

\section{INTRODUCTION}

There are a number of industries in the Alto Paranaiba and Triângulo Mineiro mesoregions in the State of Minas Gerais and in the State of São Paulo that utilize boilers fired by eucalyptus chips. When burnt in boilers, eucalyptus chips produce ashes as a residue from the incineration process. Provided their granulometry is appropriate and their structure non-crystalline, their activity can be pozzolanic and thus suitable for producing more resistant, less porous concrete. In the event they are crystalline, they can act as a filler and also improve the concrete's properties. In both cases they are important materials to producing durable concrete.

In Brazil and around the world, it is still unclear how eucalyptus chip ashes (ECA) are disposed of. Vieira et al. [1] appraised introducing ECA into clay pottery. Results showed that clay pottery properties improve if $10 \%$ of its weight is made up of eucalyptus firewood ashes, because plasticity is optimized, water absorption diminishes and mechanical resistance increases. Melo et al. [2] examined the possibility of using ECA in concrete as a replacement for the same volume of fine aggregate, but were unsuccessful, because of the decrease in mechanical strength compared to the benchmark material. In this paper we analyze the adding of different amounts of ECA into cementitious composites that were appraised for compressive strength, tensile strength subject to diametral stress, and tensile strength under bending.

\section{MATERIALS AND METHODS}

The ash samples were collected at DPA - Nestlé S/A's industrial plant in Ibiá, Minas Gerais. The raw ashes were oven-dried to constant mass at temperatures between $60-65^{\circ} \mathrm{C}$ for two days. The ashes were ground in a ball mill and re-burnt in a muffle furnace for 2 hours at $600^{\circ} \mathrm{C}$, then cooled inside it. 
ECAs were characterized by MEV and EDS. Semi-quantitative analyses were done on different areas of the sample to estimate the samples' average chemical composition. Differential thermal analysis (DTA) and the thermo-gravimetric analysis (TGA) were done.

To appraise the use of ashes as an additive in cementitious composites, bodies of proof were fashioned with partial mass of ECA, replacing the same percentage and quantity of cement, as shown in Table 1. Twelve cylinder-shaped and three prismatic bodies of proof were cast for each composite.

Table 1 - Mass values $(\mathrm{kg})$ of materials used to fashion the cementitious composite.

\begin{tabular}{l|c|c|c|c|c|c|c|c|c|c}
\hline \multirow{2}{*}{ Materials } & Control & \multicolumn{3}{|c|}{ Raw ash } & \multicolumn{3}{c|}{ Ground ash } & \multicolumn{3}{c}{ Reburned ash } \\
\cline { 2 - 13 } & $0 \%$ & $5 \%$ & $10 \%$ & $15 \%$ & $5 \%$ & $10 \%$ & $15 \%$ & $5 \%$ & $10 \%$ & $15 \%$ \\
\hline Cement & 624.00 & 592.80 & 561.60 & 530.40 & 592.80 & 561.6 & 530.40 & 592.80 & 561.60 & 530.40 \\
\hline Ash & 0.00 & 11.60 & 23.20 & 34.80 & 20.38 & 40.75 & 61.13 & 24.60 & 49.20 & 73.80 \\
\hline Water & 300.00 & 300.00 & 300.00 & 300.00 & 300.00 & 300.00 & 300.00 & 300.00 & 300.00 & 300.00 \\
\hline Natural sand & 1872.00 & 1872.00 & 1872.00 & 1872.00 & 1872.00 & 1872.00 & 1872.00 & 1872.00 & 1872.00 & 1872.00 \\
\hline
\end{tabular}

On the $28^{\text {th }}$ day, the composites' mechanical behavior was appraised on the basis of the compressive strength test and the tensile strength test subjecting the $50 \mathrm{~mm}$ diameter, $100 \mathrm{~mm}$ tall, cylindrical specimens to diametral stress. A bending tensile strength test was done on the 40x40x160 mm prismatic specimens.

\section{RESULTS AND DISCUSSIONS}

Energy dispersive $\mathrm{x}$-ray spectroscopy determining semi-quantitative chemical composition detected $\mathrm{Mg}, \mathrm{Al}, \mathrm{Si}, \mathrm{P}, \mathrm{S}, \mathrm{Cl}, \mathrm{K}, \mathrm{Ca}, \mathrm{Ti}, \mathrm{Mn}$ and $\mathrm{Fe}$, as shown in Table 2 and Figure 1 . The loss on ignition test showed that raw ECA, ground ECA and re-burnt ECA samples were 47.5\%, 51.5\% and 15\% respectively. Despite it being a qualitative analysis, the data show that the ashes have a low silica and high calcium content. This could suggest that the ashes might not have pozzolanic activity. Furthermore the samples' high calcium content may have favored formation of a hydrated calcium silicate, which generally has fewer faults due to a higher calcium/silica ratio, and could affect resistance to the alkalis of the composite made with the ashes [3].

Table 2 - Semi-quantitative results obtained via MEV for the raw ash sample.

\begin{tabular}{l|l|l|l|l|l|l|l|l|l|l|l}
\hline Element & $\mathrm{Mg}$ & $\mathrm{Al}$ & $\mathrm{Si}$ & $\mathrm{P}$ & $\mathrm{S}$ & $\mathrm{Cl}$ & $\mathrm{K}$ & $\mathrm{Ca}$ & $\mathrm{Ti}$ & $\mathrm{Mn}$ & $\mathrm{Fe}$ \\
\hline Raw ECA & 2.9 & 8.1 & 2.1 & 2.2 & 1.7 & 2.0 & 6.7 & 56.0 & 2.8 & 0.8 & 14.7 \\
\hline Ground ECA & 2.9 & 11.6 & 3.9 & 2.7 & 1.7 & 3.8 & 10.9 & 44.4 & 2.6 & 1.3 & 14.1 \\
\hline Charred ECA & 3.1 & 8.3 & 1.8 & 1.9 & 1.0 & 3.9 & 12.1 & 49.4 & 2.8 & 0.7 & 15.1 \\
\hline
\end{tabular}

Figure 1 shows micrographs of the raw ash samples amplified 20x and 100x. No long, rugged, dark fibers indicating the presence of carbon can be seen. This would confirm the ashes' low organic material content.
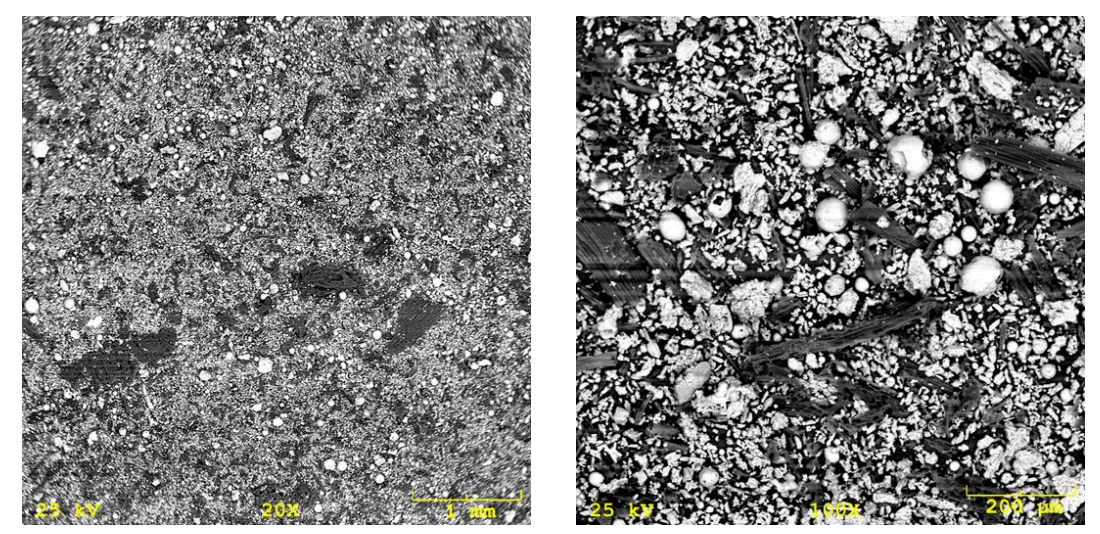

Fig. 1 - Micrograph of raw ash through a scanning microscope (20x and 100x). 
Figure 2 shows the micrograph of ground ECA amplified 200 and 1000 times. In the 200x range picture, the particles can be seen to have undergone comminution.
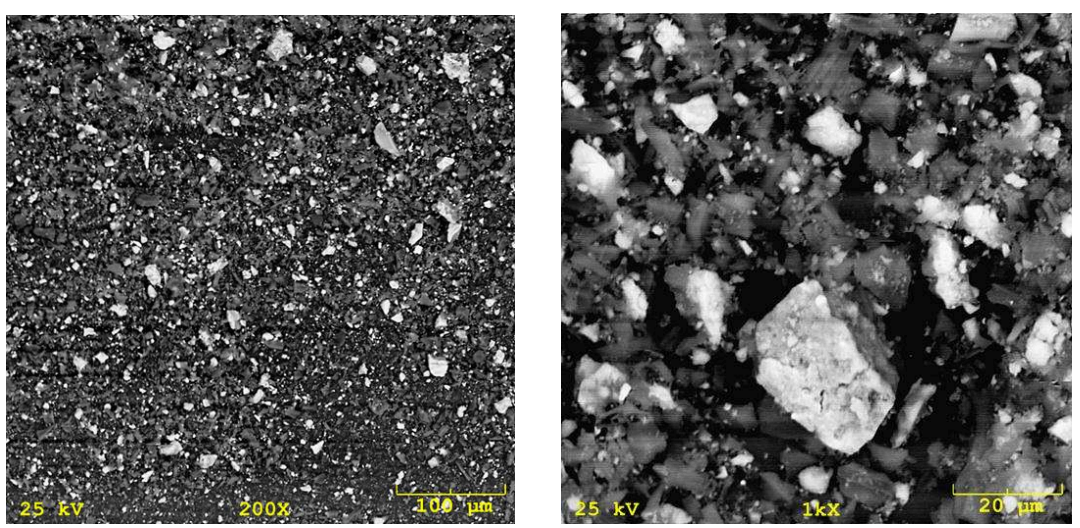

Fig. 2 - Micrograph obtained by scanning microscopy of ground ash particles (200x and 100x).

Figure 3 shows the micrograph of the re-burnt ash sample, magnified 50 and 250 times. In the 250x range picture its structure can be seen to have kept its similarity to raw ECA with no suggestion of the presence of carbon.
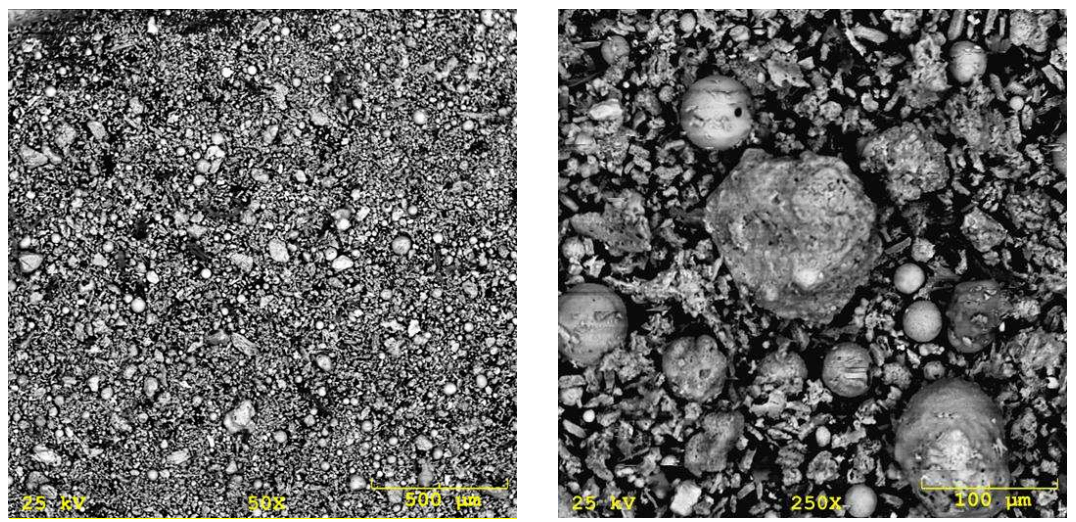

Fig. 3 - Micrograph of reburned ash particles by scanning microscopy (50x and 250x).

Figure 4 shows the curves obtained in thermal tests (DTA and TGA) for raw ECA. A slight loss of mass and an endothermic peak at about $50^{\circ} \mathrm{C}$ can be seen. This variation is probably due to loss of water adsorbed on the surface of the raw ECA. At round $500^{\circ} \mathrm{C}$ there was a significant loss of mass and an exothermic peak. Considering that the calcined ash had shown a similar composition to the non-calcined ash, this peak is likely to be related with some phase transformation and not due to loss of organic matter. 


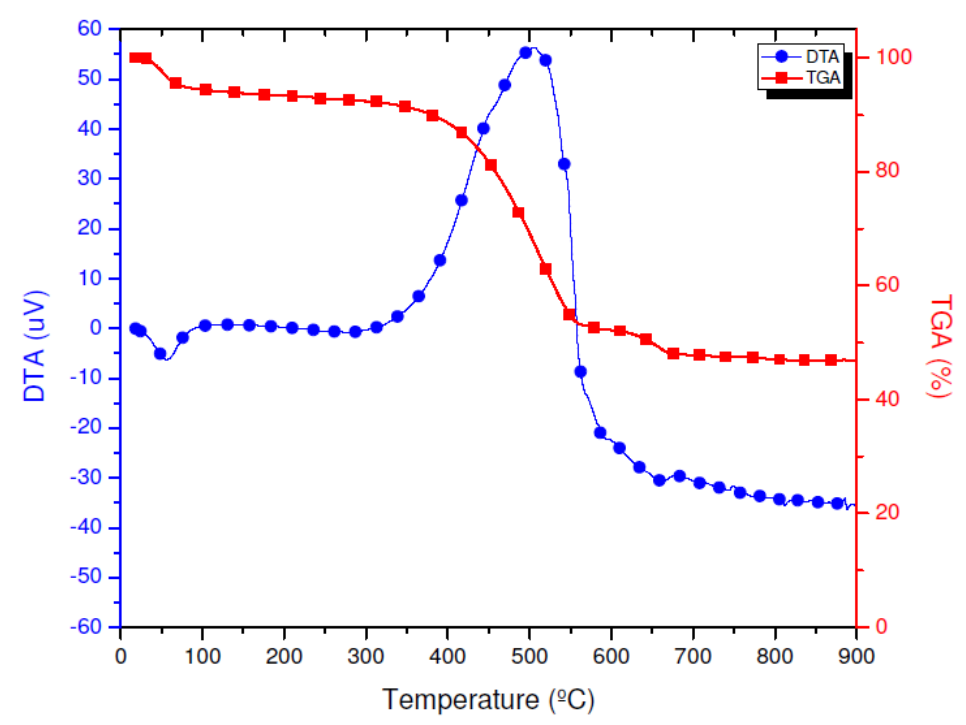

Fig. 4 - DTA and TGA of raw ECA

Figure 5 shows the results of the compressive strength test run on the cementitious composite bodies of proof featuring the various partial replacement percentages of eucalyptus chip ashes for cement. The results show that using $5 \%$ and $10 \%$ of ashes, regardless of whether they are raw, ground or re-burnt, does not jeopardize the composite's compressive strength behavior.

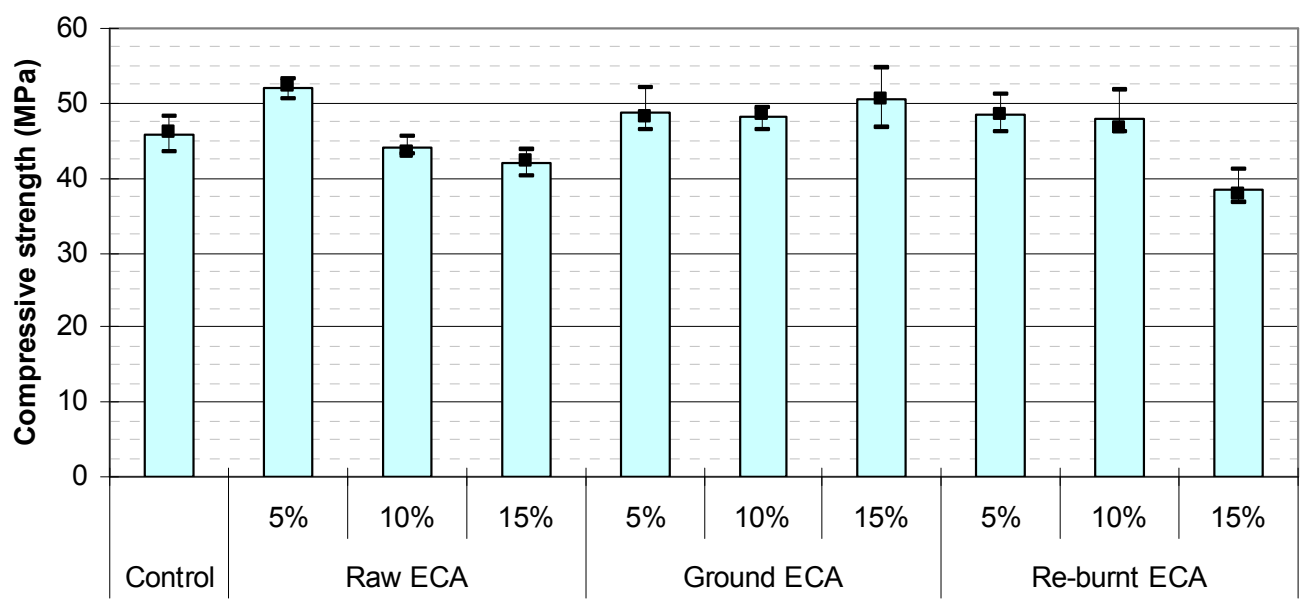

Fig. 5 - The cementitious composites' compressive strength

Figure 6 shows the results of tensile strength to diametral stress and bending. In the tensile strength to diametral stress, the composites with 5\% raw ECA and 5\% re-burnt ECA have higher values than the benchmark composite. The values of the other composites are close to the benchmark composite with the exception of the one with $15 \%$ re-burnt ECA. As to tensile strength to bending, the values of composites with additive were lower, and the results of the composite with 5\% ground ECA were considerably lower. 


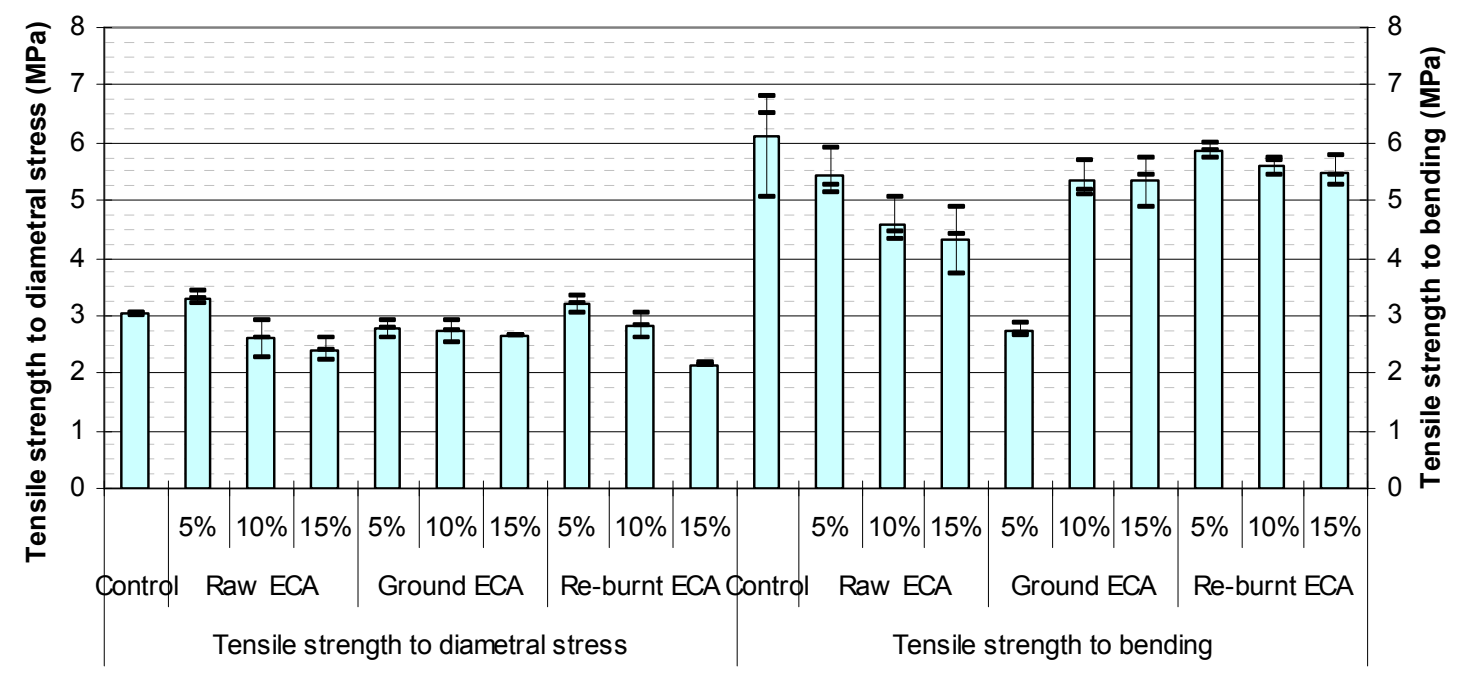

Fig. 6 - Tensile strength of the cementitious composites

\section{CONCLUSIONS}

Adding eucalyptus chip ashes as 5, 10 and 15\% in volume as partial replacements for Portland cement did not jeopardize the cementitious composites' compressive strength. At the same time, mechanical and thermal treatments do not seem to affect the performance of the ashes.

In general adding eucalyptus chip ashes did not jeopardize tensile strength under diametral stress.

Adding eucalyptus chip ashes in the proportions studied led to lower bending strength values. Considering the low contents of silica in the different ashes and these results, it could be stated that the action mechanism of ashes is likely to be one of filling larger pores. As the effect on bending was not beneficial, it is unlikely that the finer pores were filled.

The results show that immobilizing eucalyptus chip ashes in cementitious composites is viable, particularly when compressive stresses are the ones required.

\section{ACKNOWLEDGEMENTS}

The authors thank DPA-Nestlé, REDEMAT and FAPEMIG, CNPq and CAPES for their financial aid and for the scientific initiation grants.

\section{REFERENCES}

[1] C.M.F. Vieira, M.C. Borlini, H.F. Sales, R.A. Conte, D.G. Pinatti and S.N. Monteiro: Cerâmica Vol. 51 (319) (2005), p. 192.

[2] F.C.A.C. Melo, P.A.B.F. Souza, M.V.V.A. Sá, A.K.C. Nóbrega and K.L.A. Pereira: 53 Congresso Brasileiro do concreto (IBRACON). Florianópolis 01 - 04 de Novembro, 2011. Proceeding...Florianópolis, 2011. (SC)

[3] B. Lothenbach, K. Scrivener and R.D. Hooton: Cement and Concrete Research Vol. 41 (2011), p. 1244. 